\title{
KAIOWA MOMBE'UPY NHEMOHEMBYPY REHEGWA - RELATOS DA COSMOGONIA KAIOWÁ: IMPLICACCÕES NO CAMPO LINGUÍSTICO E NA PRODUÇÃO DA VIDA SOCIAL
}

GRACIELA CHAMORRO ${ }^{1}$

$U F G D$

MISAEL CONCIANZA JORGE ${ }^{2}$

$U F G D$

LEVI MARQUES PEREIRA ${ }^{3}$

$U F G D$

\begin{abstract}
RESUMO: $O$ presente artigo procura demonstrar a relevância dos relatos e ensinamentos míticos apontada pelos Kaiowá nos modelos e práticas de produção e reprodução da vida social de suas comunidades. Constitui-se, ainda, num esforço de identificar alguns elementos que apontam para sua cosmogonia. Os dados etnográficos resultam da pesquisa desenvolvida pelo professor kaiowá Misael Concianza Jorge, no trabalho de conclusão de curso do curso de Licenciatura Intercultural - Teko Arandu, da Faculdade Intercultural Indígena da Universidade Federal da Grande Dourados. Posteriormente, as outras autorias analisaram o material com o estudante para apresentá-lo na forma de artigo, acrescentando discussões bibliográficas e dados etnográficos levantados por elas. O mito é apresentado neste artigo como uma linguagem que expressa, através de recursos ritualísticos e poéticos, vários aspectos da ética e da estética kaiowá. Tais relatos fornecem códigos para os modos de relação entre os Kaiowá e entre eles e seus outros. Entre outras implicações, eles explicam a disposição de elementos da paisagem. Mas, além de tudo isso, o mito é apresentado como obra literária, que permite ao grupo que o relata e ritualiza pensar sobre as origens, os sentidos e o fim das ordens sociológicas e cosmológicas, e, sobretudo, entretém as pessoas com palavras e imagens significativas.
\end{abstract}

PALAVRAS-CHAVE: Kaiowá; cosmologia kaiowá; mito; Panambizinho.

ABSTRACT: This article seeks to demonstrate the relevance of the mythical tales and

\footnotetext{
${ }^{1}$ Graciela Chamorro é doutora em Teologia pela ETS de São Leopoldo - RS e em Antropologia pela Philipps Universitaet Marburg. É Professora de História Indígena na Universidade Federal da Grande Dourados - UFGD, desde 2006, onde integra o corpo docente do Programa de Pós-Graduação em História. E-mail: chamorro_graciela@ hotmail.com .

${ }^{2}$ Indígena kaiowá, licenciado no curso de Licenciatura Intercultural Indígena "Teko Arandu" FAIND UFGD. Professor na Escola Municipal Indígena "Pa'i Chiquito Pedro", na Terra Indígena Panambizinho Dourados MS.

${ }^{3}$ Levi Marques Pereira é doutor em Antropologia pela USP, professor da Universidade Federal da Grande Dourados - UFGD, onde coordena o mestrado em Antropologia. Realiza pesquisas em Etnologia Indígena e é Bolsista de produtividade CNPq. E-mail: levipereira@ufgd.edu.br .
} 
teachings applied by the Kaiowa in their models and practices of producion and reproduction of the social life in their communities. It also constitutes an effort to identify some elements related to their cosmogony. The ethnographic data is from the research carried out by the Kaiowá teacher Misael Concianza Jorge in order to graduate from university. The material was later analyzed by others, along with its author, in order to present it in form of an article, adding bibliographic notes and additional ethnographic data collected by them. This article presents the myth as a special language that expresses, by means of ritual and poetic devices, various aspects of Kaiowá ethics and aesthetics. These tales provide codes for the modes of relationships among the Kaiowa and between them and their others. Among other implications, they explain the configuration of landscape elements. Furthermore, the myth is presented as a literary act, which allows the group to have ritualized tales, think about its origins, meanings and aims of the sociological and cosmological orders. Above all, it entertains the people with meaningful words and images.

KEYWORDS: Kaiowá; Kaiowá cosmology; myth; Panambizinho.

\section{Introdução}

Nos estudos históricos e antropológicos dos povos indígenas, a história oral, como um procedimento de investigação, e a tradição oral, como fonte imprescindível, estão, desde muito, associadas à pesquisa empírica e sua análise. Embora descuidada em alguns centros de estudo mais interessados em explicar as falas de seus interlocutores do que entendê-las em suas implicações sociocosmológicas, o uso da tradição oral em língua indígena é, em muitos casos, uma importante porta de entrada para a visão de mundo que os povos indígenas desenvolveram. Como Aryon Dall'Igna Rodrigues (1986, p. 27ss) escreveu, as línguas indígenas são os caminhos mais seguros que nos aproximam do pensamento indígena e, às vezes, nos permitem conhecer o outro indígena em sua própria perspectiva.

O reconhecimento da importância da língua indígena na produção etnográfica está presente mesmo quando os antropólogos não chegam a ter domínio fluente da língua. Nesses casos é comum realizarem o registro de certas categorias-chavena operação do sistema social. Um exemplo clássico desse tipo de registro são as categorias buth e mar, registrada por Evans-Pritchard (1978) entre os Nuer da África Nilótica.

Dentre várias modalidades da tradição oral, o mito constitui uma narrativa, entre outros gêneros discursivos privilegiados nos estudos 
sobre a linguagem. As narrativas míticas podem, nesse sentido, focalizar um mesmo tema por meio de diferentes perspectivas; e, nesse movimento, a linguagem estabelece conexões de sentido entre distintas histórias, combinando formas de interação entre personagens, codificando e transmitindo um número restrito de mensagens que determinado coletivo humano elegeu como central na reprodução de sua formação social.

Essa diversidade é importante, mas costuma haver um conjunto de mensagens principais, que revelam os princípios subjacentes aos múltiplos relatos e ao modo de vida da comunidade que narra. E são precisamente esses princípios que tentamos vislumbrar, neste texto, a partir de formulações linguísticas kaiowá, nas breves observações apresentadas após cada relato. Afinal, nos parece importante tentar entender o que a sociedade kaiowá nos quer dizer quando afirma a relevância dos relatos e ensinamentos míticos.

Outro aspecto enfatizado nas observações é a relação entre o relato mítico e seus elementos exteriores. Tais elementos fazem parte da experiência da comunidade narradora, a qual celebra o mito. Isto porque a ambição do mito é explicar e atribuir sentido à ordem do mundo, o que justifica sua inserção numa dinâmica de comunicação que dialoga com a história, com as práticas sociais cotidianas e com as relações interétnicas. Nesta explicação leva-se, pois, em conta a conjuntura social, uma vez que ela marca a vida da comunidade, evoca os acontecimentos míticos e a eles recorre como fonte significativa para a experiência social.

O mito se apresenta como expressão privilegiada da memória e cosmologia indígenas, como se evocar os eventos primordiais fixasse e desse sentido à trajetória de vida das pessoas e das comunidades, no tempo e no espaço. Lembrar, narrar, ouvir e celebrar mitos são momentos imprescindíveis para atualizar sentidos indissociáveis da experiência humana. É dessa forma que podemos entender a expressão registrada pelo historiador Antônio Brand, em 1977, quando discorria com o capitão kaiowá Cecílio, de Taquapery, sobre a importância das rezas. Nas palavras registradas por Brand, o capitão kaiowá teria dito: "sem nossas festas, nossa religião, nossas chichas, nós somos bichos" (BRAND, 1977, p. 3). 
Como outros povos, a comunidade kaiowá também procura explicar a origem e a destruição do mundo, dos seres humanos e dos outros seres, através de mitos. Resulta daí uma complexa cosmogênese que institui os sentidos da origem e do funcionamento do cosmo. Estes mitos são geralmente transmitidos para crianças e jovens pelas pessoas mais idosas da comunidade. Mas nem todos os mitos são conhecidos igualmente por todas as pessoas mais velhas. Assim, do complexo narrativo apresentado neste artigo, os episódios mais conhecidos por pessoas da comunidade são os relativos ao "dilúvio". Já os episódios relativos à pré-criação da terra, das avós das águas e dos seres aquáticos são conhecidos por alguns poucos especialistas.

Neste trabalho tentamos transcrever essas histórias na língua kaiowá e traduzi-las para a língua portuguesa, além de conhecer melhor as modalidades utilizadas por esse grupo indígena para relatar os acontecimentos sobre a origem integrantes de sua "literatura oral". Assim, procuramos desvendar e/ou explicar (tanto quanto possível) a relação que essas histórias têm com o presente e sua correlação com as práticas sociais e culturais. Nesse sentido, destacamos os ensinamentos que tais práticas contêm/revelam, bem como a relação entre a origem do mundo e o '[futuro] modo de ser', nhande rekorã, dos grupos kaiowá. As narrativas articulam-se, portanto, a partir da ideia de princípio ou origem, $y p y$, considerado como alicerce ou fundamento entre presente e futuro. Para mostrar, por exemplo, o lugar da história do dilúvio nos mitos de origem, transcrevemos também parte da história anterior sobre esse episódio e indicamos as muitas outras histórias resultantes desta história principal.

Nas considerações seguintes aos textos míticos, procuramos, então, associar o conteúdo da narrativa com certos aspectos considerados como fundamentais pelos grupos kaiowá para a existência da coletividade humana. Destacamos assim: a) a valorização de sua forma de linguagem para o ensino e desenvolvimento da língua e da expressão artístico-criativa; b) a conexão entre metáforas e os simbolismos dos relatos com as prescrições sociais e com as formas em que as comunidades kaiowá costumam explicar e enxergar a vida e a orientação da conduta social; c) a vinculação intrínseca ente as narrativas míticas e as performances rituais. 
A realização desse tipo de pesquisa depende muito, sem dúvida, das pessoas que conhecem essas tradições orais e estão dispostas a compartilhar e a discutir seus significados com os pesquisadores e as pesquisadoras. Nesse sentido, o presente trabalho é o resultado de um esforço consorciado entre as pessoas conhecedoras da tradição oral em sua língua materna - e que, no âmbito da comunidade local, são consideradas depositárias desses conhecimentos -, o pesquisador indígena, que assimilou a história oralmente e fixou-a por escrito e através de desenhos (CONCIANZA JORGE, 2012), a pesquisadora orientadora, que acompanhou o processo de transcrição, tradução e explicação do mito, assim como da produção do texto escrito, e o terceiro autor, que tentou situar a narrativa indígena na literatura antropológica. Acompanhemos, a seguir, as tentativas de criação da 'futura', -rã, 'terra', yvy, observando a forma como foi registrada pelo pesquisador indígena.

\section{A criação da futura terra, yyyrã}

Para os Kaiowá, existiu uma primeira terra e uma primeira geração que povoou essa terra. O primeiro casal da primeira geração era composto por Xiru Yryvera e Ha'i. O nome do homem significava "brilho das águas", e o de sua esposa, "mãe". O casal teve três filhas: Hachã Rusu, Hachã Mirĩ, Hachã Mirĩ Pahagwe. A filha mais velha do casal se casou com Jakaira Gwasu, o Grande Jakairá, dono dos alimentos, com quem teve duas filhas: Hachã Rusu, a mais velha, e Hachã Mirĩ, a menor. Naquela época, não existia ainda a terra. Os dois casais e suas famílias viviam em lugares diferentes, flutuando no ar. Então, Jakaira Gwasu tentou criar a futura terra.

Yvyrã rehegwa

1 - Upépy, Jakaira Gwasu opojái yvy arysapy ku'i kwe'i rehe, oipeju ha'e ojepyso yvyrã. Oiko hagwã onhemonhã ndie ha'e oipyso yvy, opyrendagwã oha'̃̃ ojapo. Yvyrã katu naimbaretepái ha ipererĩ eterei.
Sobre a criação da futura terra

1 - No lugar onde vivia com a sua família, Jakaira Gwasu pegou na sua mão um pouco de pó da terra, o soprou e a futura terra começou a se esticar. Para viver sobre ela, ele a esticou, para ter um lugar onde por seus pés, ele tentou fazer a terra. Mas a futura terra não 
era totalmente firme, era uma camada muito fininha e fofa.

2 - Upémaramo omoĩ ita yvy ndie ha opyrüpyrũ jey pe yvyrãre ha ohechakwaa ne 'ĩraha hatã porã yvyrã. Upépy omoĩma yvyrã apytépy peteĩ apu'ami yvy pytã terã yvyakãndire ou terra sagrada ha omoapenõ irundy kwe ko yvyrã pe y ári. Kóva ko yvyrã oipyso rire opyrũpyrũ jey ha'ekwéra ha he'i ojoupe hatã porãmaha pe yvyrã.

3 - Pe yvy oipyso rire ogwahẽmba Kandire Gwasu, Pa'i Kwararã ha Jasyrã, omopu'ã hagwã yvyrarã ha ka'agwyrã. Yvyra retére omopu'ã eirarã opaichagwa, yvy ei katu ndojapói hikwái yvyra retéry, yvýry oheja.

4 - Upépy Mba'ejára Terirõ kwéra oikose mo'ã Kuarahyrãro, Jasyrãro, Mbyjarãro, Eixurãro. Ha'e kwéra katu nokonsegíri ha oiko ichugwi kwéra opa mba'e ambue.

5 - Verandyju Gwasu upépy ojesamondog Pa'i Kwarateerãre há Jasyteerãre ha he'i: "Mba'epo ha'ekwéra nonheha'ãi". Ha'e oikwaáma voi kuri péicha gwarãha ha'e kwéra.

6 - Oúma katu ha’ekwéra omymbágwi. Ojasuka ndie voi ou. Oha'ã ha oiko ichugwi kwéra Pa'i Kwara ha Jasy.
2 - Então ele misturou pedra com a terra e pisou novamente sobre a futura terra e percebeu que ela ainda não estava bem dura e firme. Então colocou no meio da futura terra um pouco de terra roxa e encimou quatro camadas. Depois de esticar esta nova massa, ele pisou novamente sobre a futura terra e percebeu, com os demais Seres que tinham ido observar sua criação, que a futura terra já estava bem dura e firme.

3 - Depois de a terra ter sido esticada, chegaram o grande Kandire, o futuro Sol e a futura Lua ao local, para levantar as futuras árvores e os futuros bosques. No corpo das árvores, eles levantaram todo tipo de mel, somente o mel que dá na terra eles não colocaram nas árvores, deixaram-no pelo chão.

4 - Então os seres chamados Mba'ejára Tetirõ quiseram se tornar o futuro Sol, a futura Lua, a futura Estrela d'alva, a futura Plêiade. Eles, porém, não conseguiram e se transformaram em todo tipo de coisas estranhas.

5 - Então disse o grande Verandyju para o futuro verdadeiro sol e a futura verdadeira lua: "Por que eles não participam do concurso?". Ele já sabia que eles já estavam destinados a isso.

6 - Prontamente eles voltaram do lugar onde estavam pescando. Vieram com seu Jasuka [transportados na sua própria luz, no seu próprio veículo]. Tentaram o concurso e se tornaram o sol e a lua. Um ilumina de dia e outro de noite.

Na futura terra, a família era composta pelo sogro, hatyu; pela sogra, taicho; pelo genro, hanhyve; pela nora, memby rembireko; pelos pais, xiru kwéra; pelas mães, ha'i kwéra; e pelas filhas, hachã kwéra. Não há filhos, só filhas.

Há versões semelhantes a esta história recolhidas na Terra Indígena Panambizinho. O povo Kaiowá, de modo geral, se considera como o Paĩ-Tavyterã do Paraguai, 'habitante do povoado do centro da 
terra' (MELIÀ e GRÜNBERG, F; GRÜNBERG, G., 2008, p. 53). Isto porque se trata fundamentalmente do mesmo grupo étnico, cujo território foi cindido pelo estabelecimento da fronteira entre Brasil e Paraguai, após a Guerra da Tríplice Aliança (1864-1870). Os que estavam do lado paraguaio denominam-se Paĩ-Tavyterã, e os que ficaram do lado brasileiro são os Kaiowá. O centro da terra, yvy mbyte, é o umbigo do cosmo, onde tudo começou, e é ocupado pelos Kaiowá. A marca disso, observada no relato recolhido em Panambizinho, é que a futura terra só ficou firme quando foi colocada terra roxa na mistura. A terra roxa é própria da área ocupada pelas comunidades kaiowá da região denominada Ka'agwyrusu, da qual Panambizinho faz parte. A partir do centro da terra, os Kaiowá pensam e organizam o mundo. O centro da terra é também a referência de manifestação dos eventos característicos do tempo primordial, ymã gware, quando, a partir da interação entre as divindades e os antepassados dos atuais kaiowá, o ambiente natural (clima, revelo, plantas, animais, astros, etc.) e o ambiente humano foi ordenado e colocado em funcionamento.

Outra observação importante no mito é o verbo levantar com significado de criar. Jakaira Gwasu levanta a terra, omopu'ã yvy, e o próprio Jakaira Gwasu cria a terra porque precisava de um lugar para pisar, ou seja, levantar-se. $\mathrm{O}$ ato de criação é precedido pelo despertar da intencionalidade, desejo e vontade, disposições que os seres do tempo primordial - tanto as "divindades" como os "antepassados humanos" - deixaram como legado à futura humanidade, como recurso para alinhavar a formação social humana. A distribuição das disposições antropocêntricas e a importância do ato de levantar foram discutidas em Pereira (2004) e em Chamorro (2008, ver capítulo 4), sendo possível afirmar que essa ação constitui um dos principais lócus de articulação do modo de vida kaiowá.

Como muitos mitos, este também quer explicar a origem dos seres, o sentido dos fatos e as práticas sociais. Assim, ele faz referência ao fato de haver pedras debaixo da terra, à existência da terra roxa em dimensões limitadas, às diversas espécies de abelhas que produzem mel em árvores e uma espécie que se aloja em buracos dentro da terra, à luz do dia e da noite, etc. No mito, a criação da terra expande-se a partir de uma pequena porção que avança até adquirir ampla dimensão e 
consistência. Os Kaiowá costumam apresentar a criação da terra como um lençol que se desdobra e cria uma superfície fina, escondendo a realidade de outros mundos, situados acima e abaixo. A terra constituída, enquanto plano, permite fixar a morada, o espaço ecúmeno, destinado a abrigar os futuros habitantes humanos. Por outro lado, também institui a distinção entre planos: o plano terrestre, o plano celeste e o plano subterrâneo. Outros mitos, não incluídos nas narrativas aqui expostas, explicitam que cada um desses planos se destinará a formas distintas de vida. Dessa forma, o ato de "estender o lençol" também implica em criar as condições para a diferenciação das formações humanas, divinas e de outras categorias de seres. Ao se esticar a terra, ou estender o lençol, o cosmo se expande, desvelando suas inúmeras dobras.

Esta história tem muitos galhos, ou seja, outras histórias, e entre elas a do sol e da lua. Mas aqui nos cabe continuar contando a história de Jakaira Gwasu e de Yryvera, personagens principais do mito do dilúvio kaiowá, que também é uma história com muitos galhos.

\section{Yvu rehegwa ou a história de Xiru Yryvera e Xiru Jakaira Gwasu}

Como já foi visto, inicialmente existiu uma primeira geração de acontecimentos. O Grande Xiru Jakaira tentou várias vezes fazer a terra e finalmente conseguiu. Nessa terra havia animais, plantas, bosques e vários seres originais, mas ainda não havia humanos. Essa terra vai ser destruída no dilúvio. Segue o relato mítico.

\section{Yvu rehegwa Sobre o dilúvio}

1 - Jakaira Gwasu opurahéi he’ýi ndie, 1 - Jakaira Gwasu está cantando com seu ha'ete ndoikwaáiva Yryvera he'i hagwe filho, como se não soubesse que Yryvera ombovutaha $y$. (dono das águas) tinha anunciado que haveria um dilúvio.

2 - Jakaira Gwasu ojepy'amongetáma yvu rehe.

2 - Jakaira Gwasu já está preocupado com o anúncio do dilúvio.

3 - Guyratĩ, Garça, upéramo kénte va'ekwe. 3 - Guyratĩ (garça), que então era uma Ha'e he'i Jakaira Gwasúpe ndoumo'ãiha y. pessoa, chegou e mentiu. Disse que não Ha'e ijapu. Upéagwi oiko chugwi ijapúarã haveria dilúvio. Assim, Gwyratĩ deu origem 
rembypy.

4 - Hanhyvẽ katu ou ha omombe'u porã voi gwatyúpe, y ovútaha.

5 - Ko 'ápe omba 'apóma Jakaira Gwasu re'ýi kwéra. Ojapóma yryta gwasu ojesalva hagwã yvúgwi.

6 - Jakaira Gwasu re’ýi kwéra ojapopátama katu yryta gwasu.

7 - Peteĩ Temiarirõ Mirĩ oporandu Jakaira Gwasúpe: "Mba'éicha jagwereko va'erã Hachã?”. Ha'e ojepy'apy upéramo osy rusúre, onhemondy'áta upe árypy.

8 - Jakaira Gwasu he'i hemiarirõme isyrusu opytataha nha'ẽ gwasy gwýpe. Pe nha'ẽ gwasúgwi ojerekokwaa peteĩ ogusuhaupépy opyta Hachã onhangareko hagwã ýrehamymba kwéryre. Upéagwi ha'e héra Jari(a) Rysapy, Jari he'ómbáva, Jari henyhẽva ysapýgwi.

9 - Jakaira Gwasu omoĩ gwajýrype (Jari Arysapýpe) nhe'ẽ porã, ani hagwã mymba kwéry paráry pegwa oporapiti reirei.

10 - Kunhangwe ogweraha hi'upyrã ondive ho'u hagwã yryta gwasu ryepýpy.

11 - Jakaira Gwasu yvyra'ija kwéra omoĩnge yryta gwasúpy peteĩ kwimba'e ha peteĩ kunhã opáichagwa tymba kwéry apytégwi. Jakaira Gwasu re'ýi kwéra onhemboyrupa avei.

12 - Onhemboyrupámaramo mymba kwéry ha gwe'ýi kwéra, Jakaira Gwasu oho ojesamondo ýre.

13 - Jakaira Gwasu ra'y ha Tajýry (Jari(a) Ro'ysarã) ohecha y ouha chupe kwéra ha omombe'u inhirungwérape.

14 - Peteĩ Jakaira Gwasu remiarirõ he'i oikeha y yryta gwasu ryepýpy. Ha'e katu he'i reinte ra'e. Tamõi Jakaira Gwasu ojoko à mentira.

4 - O genro, porém, contou a pura verdade para o sogro, que as águas iam chegar.

5 - Os familiares do grande Jakaira estão fazendo uma grande canoa para se salvarem do dilúvio.

6 - Os filhos do grande Jakaira estão quase terminando de fazer a canoa.

7 - Um netinho disse para o grande Jakaira: "como vamos cuidar da menina [pensando que ela logo iria se tornar moça]?". O menino estava preocupado com a tia, sua segunda mãe, pois ela logo iria menstruar.

8 - O grande Jakaira respondeu para seu neto que sua pequena tia ficaria debaixo de uma grande panela, fora do barco. Essa panela se transformou na casa grande kaiowá. Ali ela ficou para cuidar da água e dos animais aquáticos, por isso ela se chama Jari(a) Rysapy, uma Jari toda molhada, cheia de orvalho.

9 - O grande Jakaira deixou para sua filha Jari(a) Rysapy boas palavras, para que ela evite que os animais do mar se matem à toa.

10 - As mulheres levam mantimento para serem comidos dentro da arca.

11 - Os ajudantes do grande Jakaira colocaram na grande canoa um casal de todo o tipo de animal. Também os filhos e as filhas de Jakaira entraram na arca.

12 - Quando seus familiares e todos os animais já estavam na arca, o grande Jakaira foi olhar se as águas já estavam chegando.

13 - O filho e a filha (Jari(a) Ro'ysarã) do grande Jakaira viram a água chegando na direção deles e foram avisar seus familiares.

14 - Um neto do grande Jakaira disse que estava entrando água na canoa, mas ele estava só brincando. Jakaira também 
hemiarirõme ha he'i chupe: "Ani péicha ere, ojeroatáne yvypóry arapyrépe”.

15 - Ko 'ánga opu'ãma yrysã, hyapúma oúvo.

16 - Jakaira Gwasu re’ýi kwéra ogweroayvúma yryta gwasúpy ohóvo.

17 - Ogwahẽmaramo jatai mátapy yryta gwasu, Jakaira Gwasu re'ýi kwéra onhapytĩma yryta jatai mátare.

18 - Ko jatai rogwe rapypa'ũgwi ojerekokwaa Jakaira gwasu re’ýi kwérape ogusu.

19 - Pe jatai rogwe rapypa'ügwi ojerekokwaa Jakaira gwasu re'ýi kwérape ogusuhaokára. Pe yvate oiko ha'e kwéra irundy ro'y.

20 - Peteĩ ro'ýpe oity ijakwaavetéva peteĩ jatai twichávahahe'i ojave gwápe péicha: "Ne'îra gweteri hypa y, japytavéta ko yvate peteĩ ro'y”.

21 - Peteĩ ro'y rire oity jey ijakwaavetéva petei jatai apingwe ha he'i jey: "Ne'ĩra gweteri hypa y, japytavéta ko yvate peteĩ ro'y'. Upéicha oity araka'e Ijakwaavetéva yvaapingwe mbohapyhairundy ro'y hápe.

22- Irundy ro'y rire hypáma yhaogwejy Jakaira Gwasu re'ýi kwéra Jataigwi, pindogwasúgwi ogwejy yvy etépy. Ogusu ha okara ndie ogwejy. Ogwejy avei mymba kwéry ijave. segurou seu neto e disse: "Não anuncie isso, pode cumprir-se o que diz, a água pode entrar na grande canoa"

15 - Agora já se levanta uma onda gigante. Vem fazendo muito barulho.

16 - Os familiares do grande Jakaira aclamam a grande canoa, que começou a se mover.

17 - Quando a canoa chegou no topo de um pé de jataí, os familiares de Jakaira amarraram a arca no jataí.

18 - O lugar onde brotam as folhas do jataí se transformou numa grande casa kaiowá para os familiares de Jakaira.

19 - Esse lugar transformou-se numa grande casa e terreiro kaiowá. Ali todos viveram por quatro anos.

20 - Quando completou-se um ano, a pessoa mais sabida jogou para baixo um caroço grande de jataí e disse para as pessoas da sua idade: "Ainda não secou a água, temos que ficar aqui em cima por mais um ano".

21 - Depois de um ano, a mesma pessoa jogou novamente um caroço de jataí e disse outra vez: "Ainda não secou a água, temos que ficar aqui em cima por mais um ano". E assim ele voltou a jogar um caroço de jataí no terceiro e no quarto ano.

22 - Depois de quatro anos, a água secou e o grande Jakaira desceu do pé de jataí para a terra com seus familiares, com a grande casa, com os animais e com o terreiro.

Observe-se que na história os dois casais só têm filhas, não têm filhos, portanto não poderiam ter netos, temiarirõ. Perguntamos, dessa forma, como isso poderia acontecer e a resposta foi que os netos eram gwácho adotados por Jakaira Gwasu. Gwácho é um termo de origem quéchua que se incorporou ao espanhol e à língua portuguesa em regiões da fronteira brasileira que recebe influência dessa língua. Os 
Kaiowá utilizam o termo para denominar filhos adotados, mas também possuem outros termos em sua própria língua (PEREIRA, 2002). O fato de haver crianças sem pai já na primeira geração dos habitantes da terra chamou nossa atenção e perguntamos a respeito. Então, percebemos que a presença do gwácho no mito é importante por mostrar a existência histórica de mães solteiras e de crianças órfãs e abandonadas pelo genitor ou pela genitora. Esse fato no mito é ainda mais importante porque o gwácho não fica à toa, abandonado, mas é recolhido numa família. Nos demos conta, então, que, na verdade, o mito descreve também um pouco a sociedade kaiowá e guarani, que coloca, nas narrativas sobre o princípio, as práticas e os fatos de hoje, omohembypy. Os Kaiowá costumam dizer que, se na história não tivesse existido gwácho, não haveria gwácho hoje, o que difere das interpretações ocidentais, nas quais o mito espelha a realidade e não o contrário. Em outras palavras, não haveria gwácho por causa do mito, mas o mito para explicar o gwácho.

É possível propor uma segunda explicação para a existência destas famílias originais, composta por pai, mãe, filhas e netos adotados. Os dois primeiros termos (pai e mãe) indicam a relação de conjugalidade (pai-mãe), enquanto a conjunção dos dois primeiros termos em relação ao terceiro termo indica uma relação de consanguinidade (casal-filhas). Pode-se concluir que a ideologia do parentesco kaiowá se expressa preferencialmente pelo idioma da conjugalidade e da consanguinidade. Para entender a inclusão dos netos adotados, devemos nos remeter à ideologia de concepção dos Kaiowá, e tupi em geral, na qual o filho pertence ao homem, que é quem o produz, sendo o útero da mulher o local onde ele se desenvolve e amadurece. Dessa forma, o neto é, logicamente, sempre um outro, porque é filho de um tovaja, alguém distinto de mim, que ocupa a posição estrutural de meu contrário ou meu inimigo. Essa formulação se aproxima de muitas discussões da etnologia das terras baixas da América do Sul, que ressaltam a importância da afinidade como lócus central na produção da vida social.

Neste mito também há lições éticas e explicações etiológicas. As lições éticas ensinam como a futura sociedade kaiowá deverá agir. Segundo entendem os Kaiowá, já naquela época ocorreram coisas que 
Ihes mostravam seu futuro modo de ser. Por exemplo, o fato de Jakaira Gwasu adotar os gwácho significa que as comunidades kaiowá, atualmente, também têm que adotar as crianças órfãs de pai e mãe. Esse fato pode indicar também que a sociedade só se reproduz se relacionando com o outro e, de alguma forma, incorporando-o.

Ainda com relação à orientação das práticas que caracterizarão a futura sociedade humana, diga-se kaiowá, Jari(a) Rysapy, a avó do orvalho, "ser mítico das águas", ficou para cuidar da água e dos animais aquáticos. Entretanto, Jakaira Gwasu não Ihe deu apenas a incumbência do cuidado, ele "deixou para sua filha Jari(a) Rysapy boas palavras para proferindo-as - poder evitar que os animais das águas [do mar, no original] não se matem à toa". Outros mitos explicitam que os conhecimentos das "boas palavras" ou rezas, nhembo'e, foram deixadas com as diversas espécies de guardiões, ou jára, e foram compartilhadas com o xamã, que, proferindo-as, consegue negociar com os jára e acessar recursos em diversos domínios do cosmos.

As explicações etiológicas colocam na história da origem alguns costumes e algumas crenças de hoje. Por exemplo, quando no mito se diz que a garça mentiu para Jakaira Gwasu, está se projetando no passado original a crença kaiowá atual de que a garça é mentirosa. Entretanto, no mundo atual, a mentira se tornou uma característica também compartilhada pelos humanos, mas seu princípio e sua origem estão no comportamento da garça.

Do mesmo modo, no mito aparecem elementos e aspectos importantes da cultura kaiowá: a panela de barro, a importância da boa palavra para acalmar os ânimos, o pé de jataí e o jataí, a casa grande tradicional, a organização familiar, etc. Também a preocupação do menino com a sua tia que estava para menstruar e o fato de o Grande Jakairá ter deixado a sua filha fora do barco, debaixo de uma panela de barro, reflete o costume kaiowá de separar a menina-moça do resto da comunidade numa peça fechada, koty.

O mito também traz um vocabulário kaiowá que muitas vezes já não é usado na comunidade. Estas palavras são muito importantes porque enriquecem o vocabulário e revitalizam a língua. Destacamos aqui: sogro: hatyu, genro: hanhyvẽ, sogra: taicho, menina: hachã, neto: temiarirõ, família, familiar: te'ýi, barco-canoa: yryta, onda de mar: yrysa, 
acontecer: jeroata, matar: poroapiti, conhecimento, sabedoria: akwaa, arakwaa, mar: arakwaa, menstruar: nhemondy'a, transformar: jerekokwaa, intentar, representar: oha'ã.

É também importante observar que o nome da pessoa muda no mito. As duas filhas do segundo casal, por exemplo, no começo são chamadas apenas de hachã, que significa menina, sendo que no nome está indicado se é a mais velha, Hachã Rusu, ou a mais nova, Hachã Mirĩ ou Mir. Num momento do relato, elas ganham o nome das personagens que viriam a se tornar mais tarde, Jari(a) Ro'ysarã, Futura Avó dos seres frios, e Jari(a) Rysapyrã, Futura Avó do Orvalho. As irmãs se tornam donas-protetoras, jára, ou matrizes dos seres tutelados por elas. Comparadas com "sereias" do imaginário não indígena, a elas estariam sujeitos os seres das águas. O futuro nos seus nomes está indicado pelo marcador temporal de substantivos -rã, que desaparece quando o tempo do relato avança. Seus nomes ficam, pois, Jari(a) Ro'ysã e Jari(a) Rysapy.

Por que este mito do dilúvio é um mito kaiowá? Muitos podem achar que ele é uma cópia do relato do dilúvio da Bíblia, mas, apesar das semelhanças do yryta gwasu com a arca de Noé (em ambos se salvaram um casal de todos os animais e uma família humana), o mito é indígena. Nesse sentido lembramos que, desde o século XVI, os missionários da costa e do interior do Brasil, assim como os do Paraguai, escreveram que os povos que falavam uma língua parecida à língua kaiowá acreditavam nesse dilúvio. No mito kaiowá, ao contrário do mito da Bíblia, o dilúvio não foi um castigo, não aconteceu por causa do pecado. O mito fala que Xiru Yryvera, personagem semelhante a Noé, decidiu o dilúvio, mas não se relata que ele estava castigando seu genro Jakaira Gwasu. A futura terra simplesmente foi destruída e os dois foram os responsáveis por isso. O mito não está inserido numa perspectiva moral maniqueísta, preocupada em instituir uma separação ontológica entre bem e mal, nem em punir os maus. Ele coloca-se como um movimento fundador da sociedade humana kaiowá, em toda sua integridade, inclusive com suas limitações e imperfeições.

Mas talvez mais importante que a questão moral seja o lugar reservado à diferença, à troca e à predação. No mito da criação da primeira ou futura terra, ao tomar um punhado de pó, expandi-lo, 
acrescentar terra roxa (/atossolo) e pedra para dar consistência, foi possível estender o plano terrestre. Sua extensão produziu distintividade no plano horizontal e a criação de um plano sólido diferenciou o que está em cima e em baixo. A produção de distintos espaços e patamares está intrinsecamente vinculada ao surgimento de seres a eles relacionados. Desse modo, viver num espaço tão heterogêneo impõe a necessidade do intercâmbio e da festa, necessários à produção da sociabilidade. Quando a reciprocidade -joja não é possível ou desejável, então a saída é predar. E vários outros mitos kaiowá, que não tratamos no presente artigo, discorrem sobre a predação, que muitas vezes recai sobre o personagem anhã, espécie de ser excessivamente outro, um afim radical, irredutível à posição de afim real, que só pode ser predado ou eliminado.

Como dissemos, esta história do dilúvio é como um tronco do qual nascem muitas outras histórias conexas, que transmitem mensagens eleitas como fundamentais para a produção da vida social kaiowá, ou, como eles costumam dizer, "isso aconteceu naquele tempo, nos tempos antigos, ymã gware, para ficar de exemplo para nós". Uma dessas histórias é a de Jari(a) Ro'ysã, que passamos a narrar brevemente.

\section{O mito do surgimento da Jari(a) Ro'ysã, Kaja'a Rembypy}

Como foi visto na história anterior, a filha mais velha de Jakaira Gwasu e Ha'i se transformou em Jari(a) Rysapy, a primeira sereia, que é a protetora dos animais aquáticos. Quando ela foi colocada debaixo da panela de barro, seu pai e sua mãe deixaram milho, batata, moranga, cana-doce, abóbora e mandioca para ela se alimentar. Estes alimentos se tornaram comidas típicas do povo kaiowá e a panela se transformou na casa grande kaiowá, a ogusu.

Mas a história da segunda sereia, Jari(a) Ro'ysãa, é mais complicada, como pode ser vista a seguir. 
hagwã ypýpy.

2 - Ikypy'ýry katu araka'e onhehenõi Jari(a) Ro'ysã. Péa oho ave kaja'arã ramo ha upéagwi opyta Jari(a) Rysapy kypy'ýramo. Ha'e ninko araka'e omenda nhemi Mborevi rehe. Itaita ha'e isy, ha'i, oikwaa teĩ upéa, oikwaáma voi ogwerekoha tajýry Mborevi.

3 - Jari(a) Ro'ysã voi oho ra'e ojo'o jety ombichy hagw'a ha ogweru avati ojapo hagwã kagwĩ ha ogweraha hagwã oména Mborevípe ka'aguýpy.

4 - Ogwahẽvo ka'aguýpy ha'e ombopu peteĩ yvyrápy pindorete, ombopu hatã oinupã jave yvyrápy.

5 - Ogwahẽma jave hendápe Mborevi, Nhanderu gwasu rajy ome 'éma ichupe kagwĩ ha jety mbichy. Upéicha ogwereko ichupe araka'e pe Mborevi.

6 - Pe Mborevi Kénte voi ra'e Jari(a) Ro'ysarãme. Otaitápy ha osýpe katu ha'e mymba ka'aguy ra'e.

7 - Jari(a) Ro'ysarã ohayhu eterei Mborevípe ha Mborevi oikwaa ohayhu ave ichupe kénteicha.

8 - Ha’i ha hiu ombyasy eterei gwajýry ojepota hagwére Mborevíre. Onhe'ẽ jave ha'e kwéra upéare, ohendu Jari(a) Ro'ysarã kyvýry ha ojepy'a mongeta pe mba'e rehe, oporãndu ijeupe mba'épa ha'e ikatu ojapo.

9 - Peteĩ árypy, pe Jari(a) Ro’ysarã oho jeýma jave ojo'o jety há'e ojoso avati oména Mborevípe gwarã, ikyvýry upe aja ohóma katu ka'agwýpy ombotavy hagwã Mborevípy. Ogwahẽma jave ombopúma pindo mata. Mborevi oripara oúvy, oimo’ãgwi Jari(a) Ro'ysarã jeýma ogwahẽha oúvy.

10 - Ohechávo Mborevípe Jari(a) Ro'ysarã kyvýry onhyvõ ichupe há ojukaite ichupe. Tyvýry omboesa'ipa pe Mborevi retekwe nhemĩháme pono ohecha gweindýry oikóva.

11 - Jari(a) Ro’ysarã upe jave ojapopáma para viver no meio das águas.

2 - Sua irmã mais nova, no entanto, foi chamada de Jari(a) Ro'ysã. Ela também foi destinada para ser protetora dos seres aquáticos. Naquele tempo, ela tinha se casado secretamente com uma Anta. Seu pai e sua mãe já perceberam isso, que sua filha estava namorando um animal.

3 - Jari(a) Ro'ysã pegava e assava batatadoce, colhia milho e fazia dele chicha, depois levava esses alimentos para seu esposo Anta, no mato.

4 - Quando chegava na mata, ela tocava com uma madeira o pé da palmeira [pindó], o que produzia um som muito forte.

5 - Mal chegava no lugar onde vivia o Mborevi, a filha de Nhanderu gwasu lhe dava chicha e batata assada. Assim a teve por muito tempo a anta.

6 - A Anta era pura gente para a Futura Jari(a) Ro'ysarã. Para seu pai e sua mãe, porém, ele era bicho do mato.

7 - A Futura Jari(a) Ro'ysã amava muito a Anta e a Anta também amava a Futura Jari(a) Ro'ysã como se fosse gente, pessoa.

8 - A Mãe e o Pai se entristeceram muito porque sua filha ficou encantada pela Anta. Certa vez, o irmão mais novo da futura Jari(a) Ro'ysã ouviu a conversa de seu pai e de sua mãe a respeito e se perguntou o que poderia fazer para resolver a situação.

9 - Certo dia, enquanto a futura Jari(a) Ro'ysã saiu novamente para pegar batatadoce e pilar milho para seu esposo Anta, seu irmão foi para o mato enganar a Anta. Chegando lá, ele tocou o pé de pindó. A Anta veio correndo, achando que tinha chegado a futura Jari(a) Ro'ysã.

10 - Ao ver a Anta, o irmão da futura Jari(a) Ro'ysã o flechou e o matou. Ele picou o corpo de sua presa às escondidas, para que sua irmã não visse o que estava acontecendo.

11 - Enquanto isso, Jari(a) Ro’ysarã já tinha 
oména Mborevi rembi'urã ha ogwera jey mo'ã ichupe ka'agwpypy.

12 - Ogwahẽvo ka'agwýpy ha'e ombopu heta rei pindo mata oménape osẽ hagwã; ha'e katu nosẽi.

13 - Ojevy jeývo Jari(a) Ro’ysarã gwógapy, oike kotýpy onhenõ hagwã kyhápy, pe koty onhemosãingo hagwépy oména ro'o kwe pehẽngwe. Onhenõvo otyky hese omena rembokwe rugwy, ikyvýry omosãingo va'ekwe kyha ari.

14 - Jari(a) Ro'ysã upépy onhandu oména ojejuka hagwe. Ha'e onhembyasy eterei ha onhemoyrõ. Upéagwi oho kaja'arã. Ha'e oipyhy omynakũ ha oho ojahu. Isy he'i ikypy'ýry Miĩpe: "ekwa nde ryke rapykwéry oho kuri ojahu”.

15 - Upéma ramo miĩ oho tykéry rapykwéry ohecha hagwã mba'épo ojapo. Ogwahẽ jave miĩ ohecha gwykéry ojahuha ha'e ohenõiha ichupe: "eju jajahu”.

16 - Miĩ oipe'a oyvoty ha ojahu gwykéry jave. Upéi Miĩ he'i gwykérype che ro’ýma ha tykéry nohendúi. Ha'e pe onhepyrũma ombopu y ha he 'i: "kaja'arã ramo kuri che". Péa ohendúvo ikypy'ýry osẽ ýgwi ha ohenói jevy gwykérype. Pépy onhandúma Mĩ gwykéry ýpy gwãrãháma voi ha'e.

17 - Upéi y onhepyrüma ono'õ ha tykéry he'i miĩpe: "ekwámai nde, che aháta kaja'arã ramo". Upéma ramo ikypy'ýry oma é jevy ha ohecha pe y haĩmetéma oĩha guykéry ku'a rupi.

18 - Ogwahẽvo omombe'u osýpe há gúpe guykéry kaja'arã ramo opytaha. Nhanderu Gwasu ha ha'i katu oikwaáma voi mba'épo ojehútaha imembýrype.

19 - Pyhareve oho Nhanderu gwasu onhemonhe'ẽ hagwã gwajýrype ha ohecha pe feito a comida para seu esposo Anta e foi levar-lhe na mata.

12 - Ao chegar na mata, ela tocou em vão o pé da palmeira [pindó]. Seu esposo não saiu.

13 - Ela voltou para casa e entrou no quarto para deitar na rede, no quarto onde estava dependurado o corpo de seu esposo partido em pedaços. Ao deitar-se pingou nela o sangue do pênis de seu esposo, que seu irmão pendurara sobre a rede.

14 - Nesse instante, Jari(a) Ro'ysã percebeu que seu esposo tinha sido morto. Ela caiu em profunda tristeza e se enfezou. Por isso ela partiu para ser protetora dos seres frios. Ela pegou o cesto típico kaiowá e foi se banhar. Sua mãe disse então para sua outra filha menor, Mĩ̃: "Vá correndo atrás da tua irmã mais velha, que saiu para tomar banho".

15 - Mĩ saiu correndo, para ver o que sua irmã estava fazendo. Ao chegar, ela viu que sua irmã a chamava dizendo: "Vem, vamos nos banhar".

16 - Mĩ̃ tirou o enfeite da sua cabeça e entrou na água para se banhar com sua irmã. Mas logo ficou com frio e quis sair. Sua irmã não ouviu a reclamação e começou a bater na água dizendo: "Para ser dona-protetora das águas sou eu". Ao ouvir isto, Miĩ saiu da água e chamou novamente sua irmã e percebeu que a mesma era destinada para as águas.

17 - A água começou a se juntar e a crescer em torno da futura Jari(a) Ro'ysã, que disse para Mir: "Vai embora, eu vou ficar para ser dona-protetora dos seres frios". Miĩ voltou a olhar e viu que as águas quase alcançavam a cintura de sua irmã.

18 - Ao chegar em casa contou para seu pai e sua mãe que sua irmã ficou para ser a protetora dos seres frios. Nosso Grande Pai e Nossa Mãe, porém, já sabiam que isso iria acontecer com sua filha.

19 - De manhã Nosso Grande Pai foi aconselhar sua filha e viu que a água tinha 
y ono'õ, ojepyho twicha etereiha. Upépy ojerekokwaa peteĩ ongusu oiko hagwã áry paha peve gwarã. Nhanderu araka'e omoĩ nhe'ẽ porã gwajýry akãymy, pono umĩ hymba kwéry oporoapiti yvypóra rapype rehe. He'i araka'e péicha ichupe:

20 - "Nde ninko jerovíaharã ramo erepytáta, ani kuri mba'e vai eremoĩ teĩ nde akãymy, pono y ha nde rymba ro'o úramo ore rasy, pono ave umĩ yvypóra rapyrépe ojehu reirei ýgwi mba'asy ha avei pono imbora' $u$ '.

21 - Kóicha, heta mba'e araka'e he'i gwajýrype Nhanderu. Péagwi hechakáry kwéra ombohéry Jari(a) Ro’ysã. Y ryepýpy gwãrã voi ha'e araka'e onhemoyrõ mborevirehe, péicha araka'e ojehu nhande rembypyrã. crescido muito. Esse lugar se tornou uma casa grande que pode durar até o fim dos tempos. Nosso Pai então colocou boas palavras na cabeça de sua filha, para que os seres aquáticos não matem à toa os seres terrenos da segunda geração. Ele disse:

20 - "Você vai ficar como um ser de confiança, não coloque nada de ruim na sua cabeça, para que as águas e os animais carnívoros das águas não nos façam sofrer, para que os seres terrenos não se deparem à toa com doenças e para que não tenham maus presságios”.

21 - Assim, Nosso Pai disse muitas boas coisas para sua filha, que recebeu o nome de Jari(a) Ro'ysã, das pessoas que enxergam longe, hechakáry. Ela foi destinada a viver nas águas, ela que tinha se enfezado por causa da Anta. Isso aconteceu para dar princípio ao que pode acontecer [conosco ainda hoje].

Jari(a) Ro'ysã tinha se casado secretamente com uma Anta, mas fazia diariamente suas obrigações, seguindo um comportamento normal. Na hora do almoço e da janta, ela ia para a mata e tocava com uma madeira o pé da palmeira. Esta soava como um tambor e com isso Jari(a) Ro'ysarã chamava a anta para lhe dar de comer. A mãe começou a ficar desconfiada com as idas da filha para a mata. Por que ela ia sempre no mesmo horário? O pai também ficou preocupado com o provável casamento de sua filha com uma Anta.

O irmão de Jari(a) Ro'ysarã escutou a conversa entre Yryvera e Ha'i e não achou nada bom o que sua irmã estava fazendo, pois a Anta era um animal e não podia se casar com gente. Para Jari(a) Ro'ysarã, no entanto, a Anta era um homem. Ele a tinha seduzido e ela estava apaixonada. Certo dia, seu irmão achou a trilha que ela seguia todos os dias na hora do almoço e da janta. Encontrou também a madeira com a qual ela tocava o tronco da palmeira para chamar seu amado. Então ele tocou o tronco da palmeira como um tambor e, em poucos minutos, apareceu a Anta, que foi morta por ele, com yvyra para, o porrete longo feito de galho de árvore e enfeitado com urucum.

Jari(a) Ro'ysã, que não sabia nada do que tinha acontecido, estava 
na roça colhendo milho e batata para o amado. Quando trouxe os alimentos para casa, os lavou, socou o milho para fazer kagwĩ e assou a batata. Depois de tudo pronto, ela se dirigiu para a mata levando a comida. Chegando lá, pegou o tambor e começou a tocar, mas a Anta não apareceu. Ela tocou insistentemente o tambor, mas o amado não veio. Então voltou para casa e foi descansar na sua rede.

Algo lhe dizia que seu amado tinha sido morto. Nesse momento, ela sentiu pingar uma gota de sangue no seu rosto. Quando levantou os olhos, viu uma genitália masculina pendurada no galho da árvore. Ela reconheceu que era a genitália de seu amado. Então confirmou seu pressentimento. Levantou-se e, em silêncio, pegou o kambuchi vete, o cântaro verdadeiro de cerâmica kaiowá, e avisou sua mãe que iria pegar água. A mãe desconfiou da atitude da filha e mandou que sua irmã mais nova a acompanhasse.

Chegando à lagoa, Jari(a) Ro'ysã convidou sua irmã para entrar na água. Ela entrou, mas tinha frio e logo quis voltar para casa. Jari(a) Ro'ysã, contudo, não queria mais sair da água. A irmã saiu em disparada e foi avisar a mãe, pois pressentia a tragédia que iria acontecer. Jari(a) Ro'ysã se divertia na água, como quem diz para a água que quer se transformar num ser aquático. E a água lentamente foi subindo, aceitando o desejo da moça.

Na manhã seguinte, Yryvera, ao saber do corrido, decidiu ir até onde estava sua filha para dizer que ela podia viver para sempre nas águas. Ele a colocou como a segunda dona-protetora das águas, y jára. Seu pai a aconselhou desde a manhã até o pôr do sol. Quando já estava entardecendo, ele disse à filha para cuidar das águas boas e conter as águas más, soltar os animais aquáticos bons e amarrar os animais perigosos, que fazem mal às pessoas, para que eles não saiam à procura dos seres humanos.

Os Hechakáry, os líderes kaiowá que veem longe, que têm visões, dizem que esta história aconteceu e é contada para que as gerações de hoje saibam que gente deve se comportar como gente e animal deve se comportar como animal. Segundo eles, entre humanos e animais há um limite que deve ser respeitado. Os Hechakáry foram deixados por Deus para protegerem os seres humanos de relações absurdas. Assim começou a segunda geração. 
Jari(a) Rysapy surge um pouco antes do dilúvio e parece estar associada ao domínio da água que verte sobre a terra firme, e sua transformação se dá no contexto do ritual de iniciação da menina-moça. Impedida de permanecer ao lado da família na embarcação por conta de seu fluxo menstrual, improvisa-se um espaço para protegê-la, a panela de barro, que depois vai se transformar na casa típica dos Kaiowá. É no interior da panela que acontece a transformação da moça em Jari(a) Rysapy, a primeira y jára, dona dos seres das águas. A panela é um lugar de transformação culturalmente orientado, é nela que se preparam os alimentos e a chicha.

A segunda y jára, Jari(a) Ro'ysã, é tia, espécie de segunda mãe da primeira, e logicamente é filha de um afim. Ela surge depois do dilúvio e sua transformação ocorre por causa de um encantamento por um animal, onhemoyrõ mborevíre. Essa transformação tem características de tragédia, de castigo por ela ter se misturado com animal. Encontramos aí o tema da sedução e da paixão desenfreada, dos encontros amorosos escondidos e do canibalismo, pois os irmãos da moça encantada decidem assassinar o cunhado e tratá-lo como caça. Mas o que mais se destaca é a impropriedade da aproximação excessiva entre distintos domínios. A anta é imprópria para ocupar a posição de cunhado porque é portadora de uma alteridade radical, não redutível ao convívio da sociedade humana. Embora desperte o desejo e a paixão, a distância ontológica não permite que ela ocupe a posição de marido para a moça, ou de cunhado para os irmãos.

No tempo do relato se fala da "futura [segunda] avó dos seres frios", Jari(a) Ro'ysarã, que vivia enfezada, onhemoyrõ, que não se alegrava mais com nada, ndovy'avéi. E aqui aparece o tema da tristeza, considerada grave doença da alma, presságio de acontecimentos ruins na vida da pessoa ou de seus familiares. $O$ pai, sabendo o que está para acontecer, apenas aconselha a filha, mas não impede que o destino se cumpra. Ele só espera que a água não faça mal para ninguém. Nessa narrativa aparecem importantes fundamentos da pedagogia kaiowá. $\mathrm{O}$ recurso do pai para tentar demover a filha de seus intentos é o aconselhamento. Ele insiste nesse recurso, mas não consegue convencer a moça. Impossibilitado de impor sua vontade ao desejo da filha, tem de resignar-se a perdê-la, pois sabe que o caminho por ela escolhido a 
levará para uma viagem sem volta.

Resignado com a escolha da filha, resta-lhe apenas pedir "para cuidar das águas boas e conter as águas más, soltar os animas aquáticos bons e amarrar os animais perigosos, que fazem mal às pessoas, para que eles não saiam à procura dos seres humanos". A filha se transfere a outro domínio, mas não se desvincula totalmente do pai, de sua família e de sua antiga condição humana. Resta-lhe um resíduo de humanidade, que está referido ao comportamento do pai: ele soube respeitar a escolha da filha e isto permitiu que não houvesse uma ruptura radical entre eles. Outros mitos mostram, com base nesse resíduo de humanidade, que se desenvolve todo um campo de negociação entre o xamã humano e os jára, seres donos protetores, para acessar recursos alocados nos domínios específicos de cada jára. Só para citar um exemplo, saber as rezas que permitem negociar com os Kaja'a a cedência de alguns peixes é fundamental para realizar pescaria segura e produtiva.

Na história do dilúvio, dizemos que as Hachã, as meninas, não tiveram irmãos, mas na história da segunda avó das águas aparecem alguns homens que fazem parte da história, como seus irmãos. O que aconteceu? De fato, as Hachã não têm irmãos de sangue. Esses que aparecem na história são apenas irmãos por consideração, como até hoje acontece numa família kaiowá, quando cunhados, plenamente inseridos no grupo de parentesco, podem ser considerados como parentes - diga-se consaguíneos - porque a parentela local ideologicamente se apresenta como um grupo de parentesco. Nesse sentido, é comum ouvir a expressão "aqui todos somos parentes", para com isso indicar o fato de que todos os membros do grupo local se reconhecem e interagem como parentes, embora nem todos tenham relações de consanguinidade entre si. Observe-se que, como os homens kaiowá, os "irmãos" das Hachã são caçadores. O especial é que eles não mataram uma simples anta, mas assassinaram seu cunhado, ou mais provavelmente seu concunhado, o marido da irmã da esposa. Como isso pode ser explicado? Mais uma vez podemos nos remeter à alteridade radical do marido anta, que não vive na aldeia ou casa grande junto com os parentes. O animal, ao contrário, desenvolve uma vida isolada na floresta. A irredutibilidade de sua alteridade radical impede-o de deixar 
de ser um afim virtual e passar a ser um afim real ou efetivo. Seu destino é tornar-se inimigo e ser caçado pelos cunhados.

Talvez ajude lembrar que o termo tovaja em guarani significa "cunhado" e "inimigo" ao mesmo tempo. Desse modo, a história reflete não só o problema que os homens têm muitas vezes com seus cunhados, mas também as normas que prescrevem as relações na sociedade. As pessoas precisam se casar, mas não podem se relacionar sexualmente com parentes. Por exemplo, a filha não pode ter relações com seu pai ou seu irmão, nem o filho pode ter relações com sua mãe ou com sua irmã; o casamento só pode ser realizado com um estranho, com um não parente, mas não pode ser com um estranho demais, com um inimigo ou com um animal. Essa é a norma. E os Kaiowá "explicam" isso nesta história. Todo animal é potencialmente cunhado, porque ele, no princípio, era gente e hoje quer voltar a ser gente, e por isso quer se relacionar com gente, ojepotase kéntere. Todo cunhado é potencialmente inimigo, ele pode se tornar um estranho demais.

A história deixa o ensinamento de que temos que saber quem são nossos parentes e nossos outros. Quem são nossos irmãos, nossas irmãs, nosso pai, nossa mãe, nossos primos e primas, e quem são nossos potenciais cunhados. Animal não é parente. Mas, como ele quer voltar a ser gente, existem as rezas que impedem que o animal seduza uma pessoa, são as animal motĩha. Por isso, os humanos têm que se cuidar nos períodos de maior vulnerabilidade, porque, depois de seduzida, a pessoa já não se dá conta que o animal é animal e acha que ele é gente, e o pior, a pessoa também quer ser animal e nem se dá conta disso.

\section{Considerações finais}

Do ponto de vista metodológico, com este trabalho tivemos o objetivo de pôr em prática uma forma consorciada de pesquisa e de produção de material, o que julgamos muito produtivo. O material coletado mostra que o mito é uma linguagem que expressa, através de recursos simbólicos e poéticos, vários aspectos da ética e da estética da cultura kaiowá. O mito faz parte do idioma cultural próprio e distinto 
dos povos indígenas. No caso dos povos guarani-falantes, quando o acesso a esse idioma cultural se dá através da língua nativa, a empatia com a comunidade interlocutora, a compreensão da mensagem comunicada e a sintonia, ou aproximação da perspectiva e racionalidade próprias do grupo, são mais diretas.

A língua nativa permite o acesso direto não só ao que a outra pessoa diz, mas à forma como ela diz. Nesse sentido, como escreve Sérgio Medeiros, "os povos indígenas falam outras línguas, imaginam outras literaturas, têm outras matrizes de pensamento [e] colocam-se na arena pública a partir de outras [e ainda ignoradas] premissas" (apud CESARINDO, 2009, n.p.).

O mito põe em circulação essa arte verbal que antes de ser escrita é contada e criada. Acreditamos que escrever os mitos indígenas não pode, nesse sentido, substituir o narrar e o celebrar essas histórias. Tampouco precisa negar a fé nelas. O mito nas sociedades indígenas ocupa o lugar da história nas sociedades ocidentais. Na sociedade brasileira não indígena, por exemplo, as pessoas acreditam na história do Brasil, acreditam que essa história dá sentido ao Brasil, à sociedade, às pessoas. Elas acreditam que a História Ihes ensina que o estudo do passado ajuda a evitar os mesmos erros no presente e no futuro.

Da mesma forma, o mito dá justificativa ética e estética à sociedade que tem nele sua referência. $O$ mito codifica os modelos de relação, explica a paisagem e as características do solo. Mas, além de tudo isso, o mito é uma obra literária que permite, ao grupo que o relata e ritualiza, imaginar as origens e o fim, além de entreter as pessoas com palavras e imagens significativas.

Os mitos aqui discutidos contam como foi a origem da sociedade e como os diversos domínios foram estabelecidos no tempo primordial, ymã gware. Mas também informam como se deve viver no presente e sobre os riscos de se transgredir os limites entre os domínios. A alteridade é necessária, mas cada gradiente de alteridade implica num tipo específico de relação. Saber mapear esse cosmo tão diversificado e descobrir, em cada situação, como se relacionar com a alteridade aí colocada parece ser um exercício ao qual a população kaiowá devota grande atenção. Nesse sentido, o mito tem uma dimensão pedagógica importante na sociedade kaiowá. Em Panambizinho, aldeia onde vive o 
primeiro autor, os Kaiowá seguem se esforçando para contar seus mitos e, através deles, transmitir às novas gerações as mensagens herdadas dos antepassados.

\section{Referências bibliográficas}

BRAND, Antônio Jacó. Relatório da Diocese de Dourados. Dourados: Arquivo CIMI, 1977. 5 p.

CESARINDO, Pedro Niemyer. Os poetas. Folha de São Paulo. Caderno Mais. São Paulo, 18 jan. 2009. n.p. Disponível em: http://www1.folha.uol.com.br/fsp/mais/fs1801200909.htm. Acesso em: 22 de jun. 2016.

CHAMORRO, Graciela. Terra Madura, yvy araguyje: Fundamento da Palavra Guarani. Dourados: Editora UFGD, 2008.

CONCIANZA JORGE, Misael. Mombe'upy Nhemohembypy rehegwa [Sobre os mitos de origem] kaiowá: importância linguístico-social e possibilidades de uso na escola indígena. 2012. 54 f. Trabalho de Conclusão de Curso (Licenciatura Intercultural Indígena "Teko Arandu") - UFGD, [2012].

EVANS-PRITCHARD, Edward Evans. Os Nuer: uma descrição do modo de subsistência e das instituições políticas de um povo nilota. São Paulo: Perspectiva, 1978.

MELIÀ, Bartomeu; GRÜNBERG, Georg; GRÜNBERG, Friedl. Etnografia guaraní del Paraguay contemporáneo: los Paĩ-Tavyterã. Asunción: CEPAG, 2008.

PEREIRA, Levi M. No mundo dos parentes: a socialização das crianças adotadas entre os Kaiowá. In: LOPES DA SILVA, Aracy; NUNES, Angela; MACEDO, Ana Vera Lopes da Silva (Org.). Crianças Indígenas: ensaios antropológicos. São Paulo: Global, 2002. p. 168-186.

PEREIRA, Levi M. Imagens Kaiowá do Sistema Social e seu Entorno. 2004. 403 f. Tese (Doutorado em Antropologia - etnologia) - Universidade de São Paulo, [2004].

RODRIGUES, Aryon Dall'Igna. Línguas brasileiras: para o conhecimento das línguas indígenas. São Paulo: Edic. Loyola. 1986. 
Recebido em: 24/05/2015 * Aprovado em: 10/06/2016 * Publicado em: 30/06/2016 